\title{
A GAS CHROIMATOGRAPHY STUDY ON THE EFFECT OF TWO DIFFERENT CURING CYCLES \\ ON THE RESIDUAL MONOIMER CONTENT OF TWO DIFFERENT HEAT CURE DENTURE BASE RESINS.
}

KEY WORDS: Residual monomer, Curing cycle, Gas chromatography, Denture base resins

\section{Dr Joy PT* \\ Dr Bennett Atlin Correya}

\section{DrV. K Zahida}

\section{Dr Gilsa K.}

\section{Vasunni}

\section{Dr Julie George} Alapatt
Assistant Professor, Dept. of Prosthodontics, Government Dental College, Thrissur. *Corresponding Author

Associate Professor, Dept. of Prosthodontics, Government Dental College, Calicut.

Former Professor \& head, Dept. of Prosthodontics, Govt. Dental college , Calicut.

Principal, Govt.Dental college , Calicut.

Associate Professor, Dept. of Prosthodontics, Government Dental College, Thrissur.

The conversion of monomer to polymer is not complete in denture base resins and residual monomer left can cause mucosal irritation, inflammation, and allergic reactions in tissues adjacent to dentures. The mechanical properties of denture base resins have been found to be lacking with increased residual monomer content. Therefore, it is desirable to reduce the residual monomer content in the processed denture. In the present study Gas chromatography method was used to determine the levels of residual methyl methacrylate monomer of two different brands of heat cure denture base resins processed by two different polymerization cycles. The study concluded that while processing the denture sufficient length of boiling phase should be given and for each brand, manufacturer's instructions should be strictly followed while selecting polymerization cycle.

\section{INTRODUCTION}

Poly methyl methacrylate resin is used for fabrication of denture bases. Residual monomer left on curing of the denture base resin is known to cause mucosal irritation, inflammation, and allergic reactions in tissues adjacent to dentures. Due to uncured monomer the mechanical properties of a denture are also compromised. Therefore, it is desirable to reduce the residual monomer content in the processed denture. A number of methods have been used to detect the levels of residual monomer content. In the present study Gas chromatography method was used to determine the levels of residual methyl methacrylate monomer of two different brands of heat cure denture base resins processed by two different polymerization cycles.

\section{AIMS AND OBJECTIVES}

The present study aims,

1. To investigate the effects of two curing cycles on the residual monomer content of two commonly used heat cure denture base resins.

\section{MATERIALS AND METHODS}

Two heat cure denture base resins were used in this study.

(1) Trevalon Hi-high impact denture material

(2) Acralyn 'H' - cross linked denture base material

Materials, powder - liquid (P/L) ratio and manufacturers are listed below:

\begin{tabular}{|l|l|l|}
\hline Materials & P/L Ratio & Manufacturers \\
\hline Trevalon Hi & $25 \mathrm{~g} / 1 \mathrm{lml}$ & $\begin{array}{l}\text { Dentsply India Pvt Ltd, New Delhi- } \\
110017\end{array}$ \\
Acralyn H & $3: 1 \mathrm{v} / \mathrm{v}$ & $\begin{array}{l}\text { Asian acrylates, Mumbai, India - } \\
400064 .\end{array}$ \\
\hline
\end{tabular}

Two curing cycles were employed for this study as described below:

\begin{tabular}{|l|l|}
\hline $\begin{array}{l}\text { Cycle I Long } \\
\text { curing cycle (L) }\end{array}$ & $\begin{array}{l}\text { Processing denture base resin in a } \\
\text { constant temperature water bath at } 74^{\circ} \mathrm{C} \\
\text { for } 9 \text { hours with no terminal boiling } \\
\text { treatment. }\end{array}$ \\
\hline Cycle II Short & Involves processing the resin at $74^{\circ} \mathrm{C}$ for \\
\hline
\end{tabular}

curing cycle (S) 2 hours and increasing the temperature of the water bath to $100^{\circ} \mathrm{C}$ and processing for 1 hour.

\section{Specimen Preparation}

A steel disc of diameter $30 \mathrm{~mm}$ and thickness $3 \mathrm{~mm}$ was prepared. Elastomeric impression of this steel disc was made using addition curing silicone impression material. (Reprosil, Dentsply) Fig 1.

4 wax specimens were prepared from this impression by using modeling wax (Hindustan Modeling wax No 2, the Hindustan dental products, Hyderabad, India)Wax specimens were invested in denture flasks using class III dental stone (Kalstone, Kalabhai Karson Pvt Ltd, Mumbai, India ). Dewaxing was done by immersing the flasks in boiling water for 5 minutes.

Two brands of denture base resins were used; Trevalon Hi and Acralyn H. Resins were mixed according to manufacturer's instructions. Packing \& clamping were done following standard practices.

All specimens were polymerized in thermostatically controlled water bath (EWL-5501 Acryliser, Kavo company, Japan). The two curing cycles as described above were employed. The flasks were allowed to bench cool before deflasking.

After deflasking, these specimens were trimmed of flash and hand polished using 600 grit silicon carbide paper. Each specimen's thickness was individually measured by use of a vernier caliper.

A total of 4 discs were made ( 2 discs of Trevalon $\mathrm{Hi}$ and 2 discs of Acralyn H).Fig 2

Of these discs, 2 discs were made by short curing cycle, "S" and other 2 discs by long curing cycle, "L". Each of these discs were used for measuring the residual monomer immediately after processing the specimen by obtaining Six samples of equal weight and dividing them into the following categories. 
Distribution of discs for residual monomer detection is described below:

\begin{tabular}{|l|}
\hline Group 1 - AL \\
\hline Group 2 - AS \\
\hline Group 3 - TL \\
\hline Group 4 -TS \\
\hline
\end{tabular}

AL $\quad$-Acralyn, Long curing cycle

AS - Acralyn, Short curing cycle

TL $\quad$-Trevalon, Long curing cycle

TS -Trevalon, Short curing cycle

\section{METHOD OF DETERIMINING THE RESIDUAL MONOMER}

The residual monomer was analyzed using gas chromatography. The method of extraction of residual monomer from the specimens followed that described by Sadamori et $\mathrm{al}^{1}$. Each acrylic specimen was cut in to small pieces. $5 \mathrm{ml}$ of methyl ethyl ketone was added in to individual glass test tubes, each of which had a resin sample of about 0.2 $\mathrm{gm}$ in mass, which were then kept in dark place at $4^{\circ} \mathrm{C}$ for 96 hours. 10 micro liters of p-xylene was then added as an internal standard ( $2 \mu \mathrm{l}$ per ml) and centrifuged at $2000 \mathrm{rpm}$ for 15 minutes. The supernatant was then transferred in to a vial awaiting analysis using gas chromatography with a flame ionization detector. Gas chromatography was performed with Perkin Elmer Autosystem Gas chromatograph equipped with total chrome software. (Figure 3 )

The amount of methyl methacrylate was determined using standard calibration graph prepared by plotting peaks against known amounts of MMA. The residual monomer of each type of resin was given as percentage by mass of the specimen. The results were statistically analysed using MANOVA and Scheffe Test.

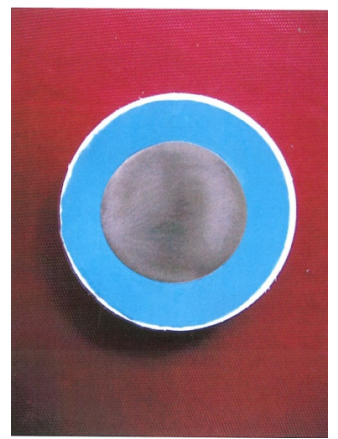

Figure: 1 Elastomeric Impression of Steel disc

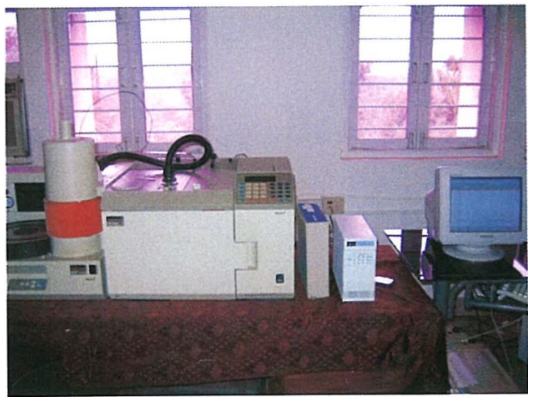

Figure:3 Perkin Elmer Gas Chromatograph

\section{RESULTS}

\section{PERCENTAGE OF RESIDUAL MONOIMER} Table I Acralyn Brand

\begin{tabular}{|l|l|l|}
\hline GROUP & (1) AL & (2) AS \\
\hline Specimen 1 & 2.21 & 1.19 \\
\hline Specimen 2 & 2.32 & 1.08 \\
\hline
\end{tabular}

\begin{tabular}{|c|c|c|}
\hline Specimen 3 & 2.28 & 1.18 \\
\hline Specimen 4 & 2.18 & 1.13 \\
\hline Specimen 5 & 2.25 & 1.16 \\
\hline Specimen 6 & 2.31 & 1.12 \\
\hline Mean Value & 2.258 & 1.143 \\
\hline \multicolumn{3}{|c|}{ Table IITreval On Brand } \\
\hline GROUP & (3) TL & (4) TS \\
\hline Specimen 1 & 2.91 & 1.34 \\
\hline Specimen 2 & 2.89 & 1.45 \\
\hline Specimen 3 & 2.90 & 1.37 \\
\hline Specimen 4 & 2.98 & 1.42 \\
\hline \begin{tabular}{|l|} 
Specimen 5 \\
\end{tabular} & 2.86 & 1.40 \\
\hline Specimen 6 & 2.94 & 1.39 \\
\hline Mean Value & 2.913 & 1.390 \\
\hline
\end{tabular}

Percentage of residual Monomer with Acralyn Brand in short and long curing cycle

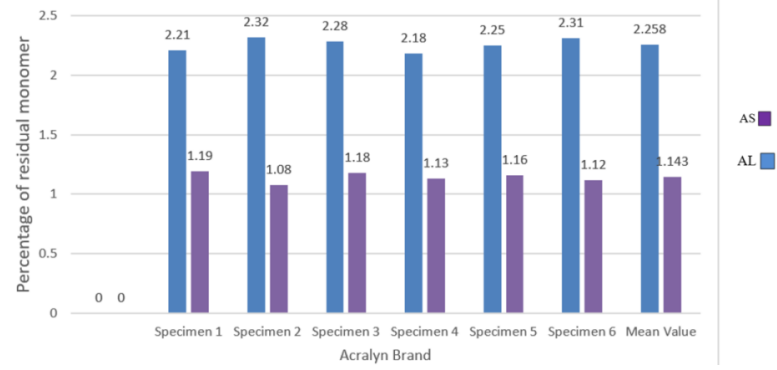

\section{Figure 5}

Percentage of residual Monomer with Trevalon Brand in short and long curing cycle

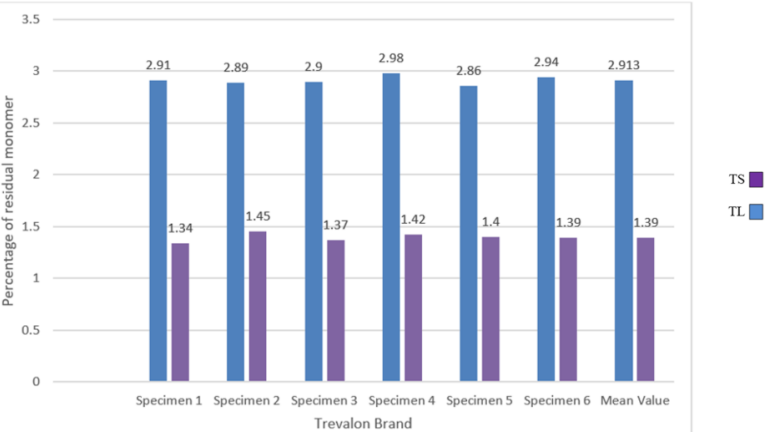

Figure 6

\section{In Acralyn Brand}

1. The highest residual monomer content was shown by specimens of group 1-AL in Table I (Mean value 2.258). The lowest residual monomer content was shown by specimens of group2-AS (Mean value 1.143). So the reduction in residual monomer content was 1.115 .

2.When the long curing groups and short curing groups were compared, the specimens cured by short curing cycles showed low residual monomer content than specimens cured by long curing cycles.

3. Statistical analysis showed that all the groups were significantly different within the Acralyn brand.

\section{In Trevalon Brand,}

1. The highest residual monomer content was shown by the specimens of group 3- TL in Table II (Mean value 2.913). The lowest residual monomer content was shown by specimens of group 4- TS (Mean value 1.390). The reduction in residual monomer content was 1.523.

2.When the long curing groups and short curing groups were compared specimens cured by short curing cycles showed a low residual monomer than specimens cured by long curing cycles.

3. Statistical analysis showed that all the groups were significantly different within the Trevalon brand. 
III. When the two brands were compared Acralyn specimens showed lower residual monomer content which was statistically significant compared to the Trevalon specimens in all conditions.

\section{DISCUSSION}

The purpose of this study was to evaluate the effects of two different curing cycles (short and long curing cycles) on the residual monomer content of two commonly used heat cure denture base resins, Acralyn $\mathrm{H}$ and Trevalon $\mathrm{Hi}$.

The conversion of monomers to polymers during the polymerization is not complete and residual monomers are invariably left in the denture base resin. This residual monomer can be leached out from the resin and can cause mucosal reactions in tissues adjacent to dentures. In addition, the mechanical properties of denture base resins like tensile strength, modulus of elasticity and surface hardness have been found to lower with increased residual monomer content. Therefore, it is desirable on both the accounts to reduce the residual monomer content in the processed denture.

Different methods have been developed to determine the levels of residual methyl methacrylate monomer like chemical methods, infrared spectroscopy, high performance liquid chromatography and gas chromatography. Gas chromatography, which is a precise and simple method to determine the residual monomer content, was utilized in the study.

Results from this study showed that short curing cycle with a terminal boiling phase significantly reduced the residual monomer content than long curing cycle without terminal boil in both the brands. This result is in agreement with the previous works of Austin and Baker $(1980)^{2}$, Huggett et al(1992) ${ }^{3}$,Jerolimov et $\mathrm{ll}^{4}$ (1985).

The effect of terminal boiling on the residual monomer content can be related to the glass transition phenomenon. The glass transition temperature, Tg of the matrix phase of the heat cured denture base resins is $97^{\circ} \mathrm{C}-100^{\circ} \mathrm{C}$. The basis for the glass transition is the onset of coordinated molecular motion in the polymer chain. At low temperatures, only vibrational motions are possible, and the polymer is hard and glassy. In the glass transition region, the polymer softens and the material becomes rubbery. Above the Tg, the monomers of the resins have a better ability to polymerize due to higher molecular chain motion and neutralization of the immobilization of residual monomer molecules in the glassy polymer. Hence the terminal boiling accomplishes more amount of polymerization and thereby reducing the residual monomer content.

The cross linking agents of the denture base polymers may also affect the residual monomer content of the polymer. The final conversion of the monomer decreases with the increasing content of the cross linking agent. This is due to the cross-linked main chain segments which are bound together via the cross-linking agent. A rigid polymer structure thus hinders the conversion of monomers especially at curing temperatures lower than Tg. So this explains the definite role of boiling phase in decreasing the residual monomer content in the polymerized resin.

Results indicated that the Acralyn specimens showed lower values of residual monomer content than Trevalon brands. This can be due to the difference in concentrations of initiator, activator, cross linking agent and inhibitor.

Jerolimov et $\mathrm{al}^{5}$, in 1989, had demonstrated the influence of benzoyl peroxide and tertiary amine (chemical activator) on the degree of polymerization. They found that higher the benzoyl peroxide content lower is the residual monomer and higher the tertiary amine content higher is the residual monomer.

It is also possible that the variation in the amounts of inhibitor and crossing linking agents may influence the polymerization. Cross linked resins on polymerization join polymer molecules in all directions forming a network of polymer molecules. Once such network starts forming it grows into a macro molecule trapping increased amount of monomer which cannot be used up by the polymer molecules already joined, and therefore such molecule of monomer remain residual are trapped within the network polymer macro molecule. It is possible that the amount of crosslinking agent can be higher in Trevalon Hi brand and therefore the residual monomer content will be also higher than Acralyn brand.

Mixing ratio between powder and liquid of each material may also have an effect on the residual monomer content. Polymer and monomer were mixed according to manufacturer's instruction ie $25 \mathrm{gm}$ powder: $11 \mathrm{ml}$ monomer for Trevalon and 3:1 by volume for Acralyn. This disparity in the polymer monomer ratio between the brands may be a contributing factor to the difference in the residual monomer content.

According to ISO specifications 1567 the maximum residual monomer content of heat cure denture base resin should not exceed $2.2 \%$ by wt. In the present study only Trevalon specimens which were processed by long curing cycle showed higher residual monomer content than recommended.

It is also worth mentioning that while selecting an optimum curing cycle apart from the residual monomer content other properties also have to be considered like strength of the resin, porosity etc. So an optimum curing cycle which allows the resin to be free of porosity, strong and with lowest residual monomer content as possible should be selected.

Hence, it can be inferred from the study that while processing the denture sufficient length of boiling phase should be given in order to reduce the residual monomer content.

\section{CONCLUSION}

Within the limitations of the study the following conclusions can be made:

In both Acralyn and Trevalon brands, the specimens cured by short curing cycle, with a terminal boiling phase showed a lower residual monomer content than specimens cured by long curing cycle. When both brands were considered Acralyn specimens showed lower residual monomer content than Trevalon specimens. While processing the denture sufficient length of boiling phase should be given. For each brand, manufacturer's instructions should be strictly followed while selecting polymerization cycle.

\section{REFERENCES}

1. Sadamori S A method of determining residual monomer in acrylic resin using methyl ethyl ketone Aust Dent J 1990;35:509-13.

2. AT Austin, RM Basker. The level of residual monomer in acrylic denture base materials. Br Dent J 149:281 1980

3. A.Harrison,R.Huggett etal.Effect of the curing cycle on residual monomer levels of acrylic resin denture base polymers.JDent. 1992;20;370-374.

4. V Jerolimov, R Huggett, SC Brooks, JF Bates, Dr odont. The effect of variations in the polymer/monomer mixing ratios on residual monomer levels and flexural properties of denturebase materials. Ouint DentTech 9:431-434 1985.

5. V Jerolimov, SC Brooks, R Hugget, JF Bates. Rapid curing of acrylic denture base materials. Dent Mater 5:18-22, 1989

6. ISO 1567 Dentistry-Denture base polymers,Berlin:Beuth;2000

7. ANUSAVICE KJ .Phillips, science of dental materials.W..Saunders; 2003. p.721-75

8. Kenneth D. Rudd. Processing Complete dentures,Dent clin North Am P 40: 141,1996

9. Robert G craig. Restorative dental materials ed:9th pg 508 Mosby 1993 